\title{
Variable innervation of the first dorsal interosseous muscle: an electrophysiological study
}

\author{
Yang Liu ${ }^{1}$, Jing Rui ${ }^{1,2,3}$, Kaiming Gao ${ }^{1,3}$, Jie Lao ${ }^{1,2}$ \\ ${ }^{1}$ Department of Hand Surgery, Huashan Hospital, Fudan University, Shanghai, China; ${ }^{2}$ Key Laboratory of Hand Reconstruction, Ministry of Health, \\ Shanghai, China; ${ }^{3}$ Shanghai Key Laboratory of Peripheral Nerve and Microsurgery, Shanghai, China \\ Contributions: (I) Conception and design: Y Liu, J Lao; (II) Administrative support: J Lao; (III) Provision of study materials or patients: Y Liu, K Gao, \\ J Lao; (IV) Collection and assembly of data: All authors; (V) Data analysis and interpretation: Y Liu, J Rui; (VI) Manuscript writing: All authors; (VII) \\ Final approval of manuscript: All authors. \\ Correspondence to: Jie Lao, MD. Department of Hand Surgery, Huashan Hospital, Fudan University, 12 Wulumuqizhong Road, Shanghai 200040, \\ China. Email: laojie633@sina.com.
}

\begin{abstract}
Background: The first dorsal interosseous muscle (FDI) is usually innervated by the deep branch of the ulnar nerve. However, as was first noted by Sunderland in 1946, some individuals have variable innervation of the FDI. This study investigated the incidence of variable innervation of the FDI by using electrophysiological examination and further evaluated the relevance of this variation in patients with cubital tunnel syndrome (CuTS).

Methods: This study included 211 patients who underwent peripheral nerve surgery in Huashan hospital, Fudan University, between October, 2012 and February, 2014. The patients were divided into three groups: the carpal tunnel syndrome (CTS) group, the CuTS group and the control group. During surgery, electromyography was used to determine FDI variation, and a hand function instrument was employed to estimate the pinch strength between the thumb and index finger in both hands of the CuTS patients.

Results: The electromyogram test showed that 22 of the patients enrolled had variable innervation of the FDI. Compared with the CTS group and the control group, the incidence of variable innervation of the FDI was much higher in the CuTS group $(\mathrm{P}<0.05)$. Patients under the age of 60 years old in the CuTS group were more likely to have the variation $(\mathrm{P}=0.043)$. A higher pinch strength ratio was significantly associated with variable innervation of the FDI in the CuTS patients $(\mathrm{P}=0.030)$.

Conclusions: Using electromyography, our study demonstrated that the variable innervation of the FDI could be innervated by the median nerve. In the CuTS patients, the higher incidence of FDI variation was possibly related to age. This variation might lead to a better prognosis for CuTS patients.
\end{abstract}

Keywords: First dorsal interosseous muscle (FDI); median nerve; ulnar nerve; variable innervation

Submitted Feb 11, 2020. Accepted for publication Sep 25, 2020.

doi: $10.21037 / \mathrm{atm}-20-1466$

View this article at: http://dx.doi.org/10.21037/atm-20-1466

\section{Introduction}

Cubital tunnel syndrome (CuTS) is a common nerve compression disease in clinic and was first reported by Feindel and Stratford (1). Tinel's sign and elbow test are useful in diagnosing CuTS, while electrophysiological examination can help to confirm the disease (2). Usually, the first dorsal interosseous muscle (FDI) is innervated by the deep branch of the ulnar nerve, which makes abnormal innervation challenging to detect. This difficulty is increased in CuTS patients, many of whom have atrophy. However, the anatomical variations in the FDI will manifest clinically. Anatomical variation of the FDI was first identified by Sunderland in 1946 (3), but in recent years, studies on this variation have been limited, especially studies that have employed electrophysiological techniques. Thus, this study aimed to investigate the incidence of this variation by using 
Table 1 The standard for grouping CuTS patients by Gu

\begin{tabular}{llll}
\hline Group & Light & Moderate & Severe \\
\hline Sense & $\begin{array}{l}\text { Intermittent sensitivity and a } \\
\text { vibration sensation }\end{array}$ & $\begin{array}{l}\text { Intermittent sensitivity and a tingling } \\
\text { sensation }\end{array}$ & $\begin{array}{l}\text { Persistent abnormality in two-point } \\
\text { discrimination }\end{array}$ \\
Motion & Weakness, less flexibility & $\begin{array}{l}\text { Weakness in gripping and pinch strength, } \\
\text { and problems in adduction and abduction }\end{array}$ & $\begin{array}{l}\text { Muscle atrophy, unable to adduct and abduct } \\
\text { Clawhand }\end{array}$ \\
NCV & $(-)$ & $(-)$ & $(+)$ \\
Treatment & Conservative treatment & Cubital tunnel release & $<30 \mathrm{~m} / \mathrm{s}$
\end{tabular}

CuTS, cubital tunnel syndrome; NCV, nerve conduction velocity.

electrophysiological examination and to further evaluate the relevance of this variation in patients with CuTS.

We present the following article in accordance with the STROBE reporting checklist (available at http://dx.doi. org/10.21037/atm-20-1466).

\section{Methods}

\section{Patient demographics}

The information of the patients who underwent a peripheral nerve surgery in the Department of Hand Surgery at Huashan Hospital, Fudan University, between October, 2012 to February, 2014 was collected. The inclusion criteria were as follows: aged 16-90 years old and diagnosed with single nerve injury in the upper extremity based on clinical symptoms and electromyography examination. Patients who were diagnosed as brachial plexus injury, thoracic outlet syndrome, cervical spondylopathy, peripheral neuritis were excluded. Gu's standards which estimated the sense, motion, muscular atrophy, nerve conduction velocity of the patients was used to diagnose the carpal tunnel syndrome (CTS) and CuTS (4). The patients were divided into three groups: the CTS group, the CuTS group and the control group. The control group comprised patients without median nerve and ulnar nerve injury. The severity of CuTS was evaluated according to the systematic estimation grades introduced by Gu (Table 1) (4). Furthermore, according to the World Health Organization's definition of an elderly person, the CuTS patients were divided into two groups: over 60 years old and under 60 years old.

\section{Electrophysiological study}

During the surgery, the concentric needle electrode (CNE) was inserted into the FDI in the middle radial side of the metacarpus of the index finger, and the surface electrode (SE) was placed on the skin where the distance was $1 \mathrm{~cm}$ proximal to the palmar transverse crease of the wrist where the median nerve and the ulnar nerve passed (5). The skin temperature was maintained above $32{ }^{\circ} \mathrm{C}(6)$. The median and ulnar nerves were stimulated at an intensity of $4 \mathrm{~mA}$ and a frequency of $3 \mathrm{~Hz}$. Then, we established whether we could record the compound muscle action potential (CMAP) in the FDI by the CNE or not. When the CMAP wave in the median nerve was larger than that in the ulnar nerve, and the latency of the CMAP in the median nerve was longer than that in the ulnar nerve, variable innervation of the FDI was recorded.

\section{Patient follow-up}

Six months after surgery, we used the hand function instrument (Pablo System, Tyromotion, Graz Austria) to estimate the pinch strength between the thumb and index finger in both hands of each patient in the CuTS group (Figure 1). To estimate strength, we instructed the patients to put their thumb and index finger on either side of the pressure sensor. The patients were then ordered to press the sensor and the strength data were recorded by the software. The pinch strength ratio was calculated by dividing the surgical-side pinch strength by the strength of the normal side. If the patient missed follow-up, we would not calculate pinch strength ratio of the patient.

\section{Statistical analysis}

The Chi square test was used to compare the incidence of variable innervation of FDI between the groups. The Mann-Whitney $U$ test was used to analyze the difference 


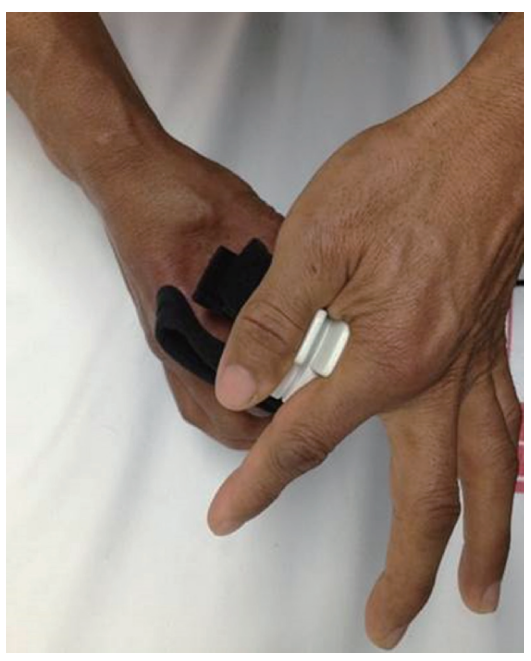

Figure 1 The pinch strength evaluation.

Table 2 Patient characteristics $(\mathrm{N}=211)$

\begin{tabular}{lc}
\hline Variable & No. \\
\hline Average age (SD) (years) & $51.46(11.91)$ \\
Range & $17-83$ \\
Affected hand & 109 \\
Left & 102 \\
Right & \\
Disease type & 128 \\
CTS group & 59 \\
CuTS group & 24 \\
Control group & \\
Disease duration (months) & \\
CTS (SD) & $16.22(34.01)$ \\
CuTS (SD)
\end{tabular}

CTS, carpal tunnel syndrome; CuTS, cubital tunnel syndrome; $\mathrm{SD}$, standard deviation.

of pinch strength ratio in the CuTS group. The association between pinch strength ratio and the variable innervation of the FDI in the CuTS patients was examined using logistic regression analysis. Receiver operating characteristic (ROC) curves were plotted to estimate the sensitivity and specificity of the pinch strength ratio to predict the incidence of variable innervation of the FDI in the CuTS patients. All data were handled using Stata 11.2 version (Stata Corporation, College Station, TX, USA). The level of statistical significance was set at $\mathrm{P}<0.05$.

The study was conducted in accordance with the Declaration of Helsinki (as revised in 2013). The study was approved by the Ethics Committee of Huashan Hospital, Fudan University, Shanghai, China (No. 2018-416) and informed consent was taken from all the patients.

\section{Results}

\section{Patient characteristics}

There were 211 patients included in this study. The patients ranged in age from 17 to 83 years old, with an average age of 51.46 years old. There were 109 and 102 left and right hands affected, respectively. There were 128 patients in the CTS group, 59 patients in the CuTS group, and 24 patients in the control group. The average disease duration was 47.61 months in the CTS group and 16.22 months in the CuTS group (Table 2).

\section{The incidence of variable innervation of the FDI determined by electrophysiological examination}

The electrophysiological examination showed that 18 of the 59 patients $(30.51 \%)$ in the CuTS group had possible variable innervation of the FDI; this was compared to 2 out of 128 patients (1.56\%) in the CTS group and 2 out of 24 patients $(8.33 \%)$ in the control group (Table 3 ). Compared with the CTS group and the control group, the incidence of variable innervation of the FDI was much higher in the CuTS group (CuTS group vs. CTS group and control group, $\mathrm{P}<0.001$; CuTS group vs. CTS group, $\mathrm{P}<0.001$; CuTS group vs. control group, $\mathrm{P}=0.032$ ). There was no significant difference between the CTS group and the control group $(\mathrm{P}=0.057)$.

In the CuTS group, there was only 1 case of variation in the over-60-year-old group, but there were 17 cases of variation in the under-60-year-old group (Table 4). The CuTS patients under 60 years old were more likely to have this variant $(\mathrm{P}=0.043)$. Among the 18 patients whose FDI was innervated by the median nerve, 9 of 19 patients were diagnosed as moderate CuTS and 9 of 40 patients were diagnosed as severe CuTS. No significant relationship was identified between FDI variation and the severity of CuTS in this study $(\mathrm{P}=0.053)$. 
Table 3 The incidence of variable innervation of the first dorsal interosseous muscle by using electrophysiological examination

\begin{tabular}{lcc}
\hline Positive results (variable) & No. & Incidence \\
\hline CTS group & 2 & $1.56 \%$ \\
Left & 0 & \\
Right & 2 & \\
CuTS group & 18 & $30.51 \%$ \\
Left & 10 & \\
Right & 8 & \\
Control group & 2 & $8.33 \%$ \\
Left & 2 & \\
Right & 0 & \\
\hline
\end{tabular}

CTS, carpal tunnel syndrome; CuTS, cubital tunnel syndrome.

Table 4 The variable innervation of the first dorsal interosseous muscle in the CuTS patients

\begin{tabular}{lcc}
\hline Variable & Positive & Negative \\
\hline Age & 1 & 12 \\
$>60$ years $(n=13)$ & 17 & 29 \\
$<60$ years $(n=46)$ & & \\
Severity of CuTS & 9 & 10 \\
Moderate CuTS $(n=19)$ & 9 & 31 \\
Severe CuTS $(n=40)$ &
\end{tabular}

CuTS, cubital tunnel syndrome.

Table 5 The association between pinch strength and variable innervation of the first dorsal interosseous muscle in the CuTS patients

\begin{tabular}{lcccc}
\hline & Coefficient & Std. err & P value & 95\% conf. interval \\
\hline $\begin{array}{l}\text { Pinch } \\
\text { strength ratio }\end{array}$ & 19.047 & 25.896 & 0.030 & $1.326,273.603$ \\
\hline
\end{tabular}

\section{Higher pinch strength after surgery was associated with variable innervation of the FDI in the CuTS patients}

The data of pinch strength of $58 \mathrm{CuTS}$ patients were collected at 6 months after surgery and 1 patient missed the follow-up. The pinch strength was significantly different between the FDI variation group and the no FDI variation group $(\mathrm{P}=0.007)$. Higher pinch strength ratio was significantly associated with variable innervation of the FDI

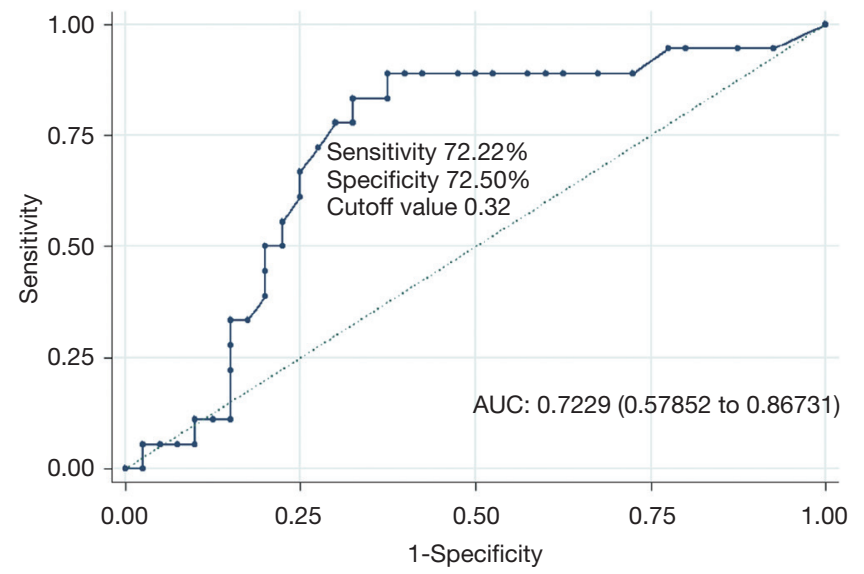

Figure 2 The receiver operating characteristic (ROC) curve for predicting the incidence of variable innervation of the first dorsal interosseous muscle.

in the CuTS patients $(\mathrm{P}=0.030$, Table 5). When using the pinch strength ratio to predict the variable innervation of the FDI, the area under the curve was 0.7229 (Figure 2). The cutoff value was 0.32 , clinical significance of which is that the FDI might be innervated by the median nerve when the ratio of the pinch strength was bigger than the cutoff value (Figure 3). The Jordan coefficient of the cutoff value was 0.4472 .

\section{Discussion}

This study found that the variable innervation of the FDI was more common in patients with CuTS, especially those of a younger age. Meanwhile, this variation might lead to a better prognosis in CuTS patients.

In clinical practice, there are patients whose symptoms of muscular atrophy did not progress at a pace equal to the severity of the corresponding nerve compression disease (7-11). Tamagawa found that the anastomosis between the median nerve and ulnar nerve in the wrist might lead to misdiagnosis in electromyography (12). Golovchinsky found that if there was anastomosis between the median nerve and ulnar nerve in the forearm, the function of the intrinsic muscle could be preserved, and the muscular atrophy was not obvious (13). In some patients, all of the intrinsic muscles could be innervated by a single nerve (14). In clinic, there are patients whose symptoms of numbness and muscular atrophy are discordant. All of these unusual symptoms suggest the presence of abnormal innervation caused by anatomical variations. 


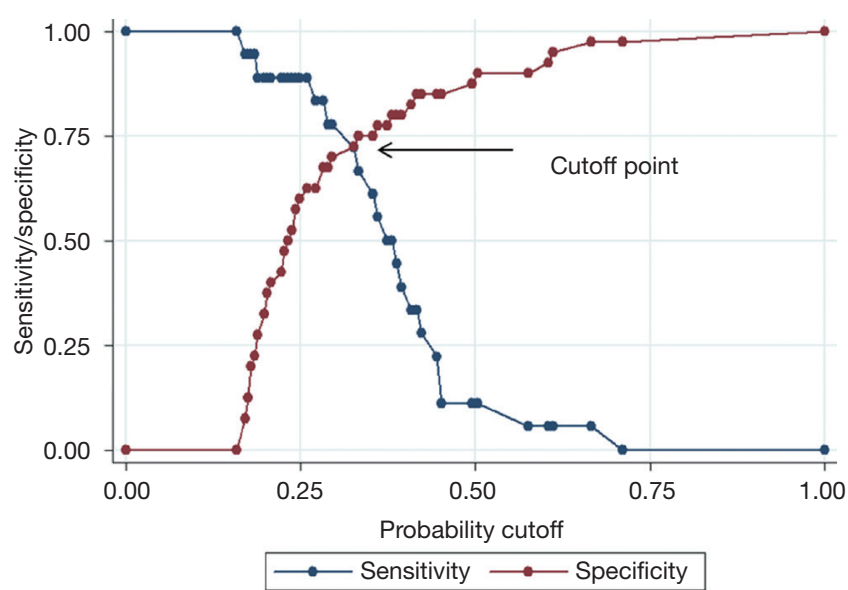

Figure 3 The cutoff point was 0.32 ; at this point, the sensitivity was $72.22 \%$ and the specificity was $72.50 \%$.

Anastomosis between the median nerve and ulnar nerve is the most common anatomical variation. Anatomical and electrophysiological studies have shown that the innervation variations of intrinsic muscles were caused by the anastomosis in the forearm and hand $(15,16)$. As the previous studies have proven, there are many anatomical variations in the population. Each of these variations has effects on vessels, organs, nervous system, and other parts of the body (17). In our electrophysiological study, the total percentage of CTS and the control group patients whose median nerve innervated the FDI was $2.63 \%$ (4/152 cases). This incidence was similar to those found in previous studies $(3,8)$.

In this study, we found that variable innervation of the FDI was more common in the CuTS group (30.51\%). In CuTS patients, the injury to the ulnar nerve could lead to the denervation of the FDI and muscular atrophy. As nerve tissues has the ability to regenerate $(18,19)$, after the compensation by other nerves, the muscular atrophy could be improved to some degree as the muscular branches that grow from the median nerve reinnervate the FDI. Furthermore, histological studies have proven that skeletal muscles could be atrophied by denervation over time $(20,21)$. Electrophysiological studies have shown that some nerve motor units are reborn after the loss of old units, which suggests that the reinnervation partly begins at the start of denervation (22). Okwueze discovered that in about quarter of the population, the FDI could also be innervated by the posterior interosseous nerve and the superficial branch of the radial nerve (23). Similarly, as previously mentioned, Sunderland (3) and Massey (8) found that the FDI could be innervated by the median nerve. Therefore, in CuTS patients, the variable innervation of the FDI by the median nerve could improve the muscular atrophy.

We also found that the percentage of younger patients with variation of the FDI is much higher than that of older patients. Previous studies have revealed that reinnervation and denervation in the motor unit is related to age. In older people, the reinnervated speed of the newborn nerve fiber is lesser than the speed of denervation $(22,24,25)$. Thus, the reinnervation of the FDI by the median nerve after injury to the ulnar nerve may be more likely to occur in younger patients, thereby improving their muscular atrophy.

In clinic, the loss of function in the intrinsic muscle caused by CuTS may recover slowly or not at all (4). Loss of intrinsic muscle function could lead to severe loss of hand function, especially fine finger movement. The recovery of the intrinsic muscle has always been a significant problem affecting the prognosis of CuTS. As the literature shows, pinch strength can be used to evaluate the intrinsic muscle function and estimate the clinical outcomes of CuTS patients (26). Therefore, we also wanted to investigate whether the ratio of pinch strength in both hands between the thumb and index finger was different between patients with and without the variation. In our study, we found that the higher the ratio of the pinch strength in the thumb and index finger between the affected hand and the healthy hand, the higher the possibility that the first dorsal interosseous was innervated by the median nerve in CuTS patients. As Doherty's study showed, reinnervation partly begins at the start of denervation (22), and the distance between the muscle and the nerve can be a factor that impacts the reinnervation speed (19). In this situation, the patients with the variation who had no injury to the median nerve that might have caused the pinch strength to recover quicker than in those patients who had no variation. The function of the intrinsic muscle might have recovered more quickly in the patients with the variation. This partly explains how the FDI variation might lead to a better prognosis for CuTS.

However, there are some limitations in our study. First, this study included a relatively limited number of cases within a short follow-up period. Further largerscale studies are needed to validate our findings. Second, electrophysiological examination is based on the volume conduction effect. As the human body is considered to be a volume conductor, the errors caused by volume conduction in measuring the nerve conduction velocity should be acknowledged (27). Nevertheless, compared to anatomical 
surgery, electrophysiological examination is a convenient and minimally invasive way to detect variation.

\section{Conclusions}

In summary, through electrophysiological examination, our study showed that the median nerve could innervate the FDI. Variable innervation should be considered when the clinical manifestation in the FDI does not progress at a pace equal to the CuTS. After ulnar nerve injury, the FDI may become innervated by the median nerve. When this variation is present in CuTS, the patient's prognosis may be better.

\section{Acknowledgments}

Funding: This study was sponsored by the Natural Science Foundation of China (grant No. 81501051 and 81572127). The funders had no role in the study design, data collection and analysis, decision to publish, or preparation of the manuscript.

\section{Footnote}

Reporting Checklist: The authors have completed the STROBE reporting checklist. Available at http://dx.doi. org/10.21037/atm-20-1466

Data Sharing Statement: Available at http://dx.doi. org/10.21037/atm-20-1466

Conflicts of Interest: All authors have completed the ICMJE uniform disclosure form (available at http://dx.doi. org/10.21037/atm-20-1466). The authors have no conflicts of interest to declare.

Ethical Statement: The authors are accountable for all aspects of the work in ensuring that questions related to the accuracy or integrity of any part of the work are appropriately investigated and resolved. The study was conducted in accordance with the Declaration of Helsinki (as revised in 2013). The study was approved by the Ethics Committee of Huashan Hospital, Fudan University, Shanghai, China (No. 2018-416) and informed consent was taken from all the patients.

Open Access Statement: This is an Open Access article distributed in accordance with the Creative Commons
Attribution-NonCommercial-NoDerivs 4.0 International License (CC BY-NC-ND 4.0), which permits the noncommercial replication and distribution of the article with the strict proviso that no changes or edits are made and the original work is properly cited (including links to both the formal publication through the relevant DOI and the license). See: https://creativecommons.org/licenses/by-nc-nd/4.0/.

\section{References}

1. Feindel W, Stratford J. Cubital tunnel compression in tardy ulnar palsy. Can Med Assoc J 1958;78:351-3.

2. Li QT, Tian GL. The Diagnostics of Hand Surgery. The People's Medical Publishing House 2009:110-2.

3. Sunderland S. The innervation of the first dorsal interosseous muscle of the hand. Anat Rec 1946;95:7-10.

4. Gu YD. Some related questions in the diagnosis and treatment of the carpal tunnel syndrome and cubital tunnel syndrome Chin J Hand Surg 2010;26:321-3.

5. Seror P, Maisonobe T, Bouche P. A new electrode placement for recording the compound motor action potential of first dorsal interosseous muscle. Neurophysiol Clin 2011;41:173-80.

6. Kim DH. Ulnar Nerve Conduction Study of the First Dorsal Interosseous Muscle in Korean Subjects. Ann Rehabil Med 2011;35:658-63.

7. Isaković E, Delic J, Bajtarevic A. Martin-Gruber anastomosis and transposition in cubital tunnel. Bosn J Basic Med Sci 2007;7:71-3.

8. Massey EW, Pleet AB. Median neuropathy affecting the first dorsal interosseous muscle. Muscle Nerve 1978;1:501.

9. Sander HW, Quinto C, Chokroverty S. Median-ulnar anastomosis to thenar, hypothenar, and first dorsal interosseous muscles: collision technique confirmation. Muscle Nerve 1997;20:1460-2.

10. Marras C, Midroni G. Proximal Martin-Gruber anastomosis mimicking ulnar neuropathy at the elbow. Muscle Nerve 1999;22:1132-5.

11. Burakgazi AZ, Russo M, Bayat E, et al. Ulnar neuropathy with prominent proximal Martin-Gruber anastomosis. Int J Neurosci 2014;124:542-6.

12. Tamagawa C, Shiga K, Ohshima Y, et al. Riche-Cannieu anastomosis and a paradoxical preservation of thenar muscles in carpal tunnel syndrome: a case report. No To Shinkei 2004;56:53-8.

13. Golovchinsky V. Ulnar-to-median anastomosis and its role in the diagnosis of lesions of the median nerve at the elbow and the wrist. Electromyogr Clin Neurophysiol 
1990;30:31-4.

14. Sachs GM, Raynor EM, Shefner JM. The all ulnar motor hand without forearm anastomosis. Muscle Nerve 1995;18:309-13.

15. Rubin DI, Dimberg EL. Martin-Gruber anastomosis and carpal tunnel syndrome: [corrected] morphologic clues to identification. Muscle Nerve 2010;42:457-8.

16. Leis AA, Stetkarova I, Wells KJ. Martin-Gruber anastomosis with anomalous superficial radial innervation to ulnar dorsum of hand: a pitfall when common variants coexist. Muscle Nerve 2010;41:313-7.

17. Moore KL, Dalley AF, Agur AMR. Clinical Oriented Anatomy. 5th edition. Philadephia: Lippincott Williams \& Wilkins, 2006.

18. Lanzetta M, Pozzo M, Bottin A, et al. Reinnervation of motor units in intrinsic muscles of a transplanted hand. Neurosci Lett 2005;373:138-43.

19. Magdi Sherif M, Amr AH. Intrinsic hand muscle reinnervation by median-ulnar end-to-side bridge nerve graft: case report. J Hand Surg Am 2010;35:446-50.

20. Ohlendieck K. Proteomic Profiling of Fast-To-Slow Muscle Transitions during Aging. Front Physiol 2011;2:105.

21. Aagaard P, Suetta C, Caserotti P, et al. Role of the nervous

Cite this article as: Liu Y, Rui J, Gao K, Lao J. Variable innervation of the first dorsal interosseous muscle: an electrophysiological study. Ann Transl Med 2020;8(23):1563. doi: $10.21037 /$ atm-20-1466 system in sarcopenia and muscle atrophy with aging: strength training as a countermeasure. Scand J Med Sci Sports 2010;20:49-64.

22. Doherty TJ, Vandervoort AA, Taylor AW, et al. Effects of motor unit losses on strength in older men and women. J Appl Physiol (1985) 1993;74:868-74.

23. Okwueze MI, Cardwell NL, Wolfort SL, et al. Unexpected motor axons in the distal superficial radial and posterior interosseous nerves: a cadaver study. Clin Anat 2007;20:790-4.

24. Rowan SL, Rygiel K, Purves-Smith FM, et al. Denervation causes fiber atrophy and myosin heavy chain co-expression in senescent skeletal muscle. PLoS One 2012;7:e29082.

25. Luff AR. Age-associated changes in the innervation of muscle fibers and changes in the mechanical properties of motor units. Ann N Y Acad Sci 1998;854:92-101.

26. Kang HJ, Oh WT, Koh IH, et al. Factors Influencing Outcomes after Ulnar Nerve Stability-Based Surgery for Cubital Tunnel Syndrome: A Prospective Cohort Study. Yonsei Med J 2016;57:455-60.

27. Gu YD, Wang SH, Shi D. Gu Yudong•Wang Shuhuan's Hand Surgery. Shanghai Science and Technology Press, 2002:169. 